\title{
Security of mind: 20 years of attachment theory and its relevance to psychiatry
}

\author{
Gwen Adshead
}

\section{Summary}

In this editorial, I suggest that no psychiatrist should be without a working knowledge of attachment theory, and it is a capability that all trainees should cover in the proposed new curriculum. I have focused on three domains of research to argue that attachment theory is relevant to practicing psychiatrists.

\section{Declaration of interest}

None.

\section{Copyright and usage}

(c) The Royal College of Psychiatrists 2018.
Gwen Adshead trained at St George's Hospital, the Institute of Psychiatry and the Institute of Group Analysis. She works as a consultant forensic psychiatrist and psychotherapist at Ravenswood House Hospital. She has a special interest in attachment theory applied to personality disorder, offending and somatising disorders.
The attachment system in humans is best understood as a biobehavioural stress management system that is activated whenever a person is distressed and vulnerable and seeks care or protection. Observational studies of children's behaviour under conditions of stress gave rise to the concept of the security (or insecurity) of the attachment bond between a child and their carer.

The attachment system is also essential for communication of distress and the need for care. Security and insecurity of attachment is manifest in the ways that people seek care, their relationships with caregivers and the language they use in those relationships. Linguistic and narrative studies of attachment in older children and adults show how the attachment bond is unconsciously represented in cognitive structures, including words and images, and how such representations might be transmitted across generations by the caregiving and care-eliciting relationship between carer and child.

In humans, insecurity of attachment is quite common in the general population (40\%), but it is nearly twice that in clinical populations. ${ }^{1}$ This high prevalence indicates that attachment insecurity is not a pathology per se, but a risk or mediation factor for the development of psychopathology when the individual is exposed to other risk variables.

\section{Attachment theory, neuroscience and social stress}

The Royal College of Psychiatrists has an active programme funded by the Gatsby Foundation and Wellcome Trust Neuroscience project to ensure that the new curriculum for trainees includes up-to-date evidence about the neuroscience of common mental disorders. The neuroscience of attachment systems is relevant here, especially in the context of the social stress and relationship disruption experienced by so many patients. The attachment system activates both cortical and subcortical structures in response to stress in social relationships. ${ }^{2}$ Attachment security has a role in preserving the resources of the prefrontal cortex, in terms of social relating ${ }^{3,4}$ and buffering against stress, which may explain why patients with mental disorders who also have insecure attachments may struggle to maintain attachments with both personal and professional carers and families, and then suffer social isolation.

One domain of social relating that is uniquely stressful is pregnancy and the postpartum period, and the neuroscientific basis of maternal behaviour has relevance for postnatal mental disorders. Maternal attachment security affects how a mother relates to her baby and how the baby's attachment system then develops in response. Strathearn et $a \bar{l}$ recruited securely and insecurely attached mothers and compared their responses to images of infants crying and smiling - both their own and a stranger's child. Secure and insecure mothers did not differ in their responses to smiling babies, but insecure mothers showed a differential pattern of brain activation in response to any crying baby. The areas of the brain that were activated in insecure mothers included areas that are known to be activated in negative emotions, including the emotion of disgust.

Lenzi et $a l^{6}$ review subsequent studies that confirm that maternal attachment security has a major effect on maternal responses to relational behaviours by infants, like crying. Such studies may have implications for healthcare professionals who have to manage other people's distress, especially in mental health. Psychiatrists need to think about how their own attachment systems may be activated by patients' distress, and distress in staff and organisations. They may need to consider how attachment activation may affect their own response to stress at work, as well as their therapeutic alliance with patients.

\section{Attachment security, childhood adversity and health in adulthood}

Studies of adverse childhood experiences (ACEs) have found a strong relationship between exposure to four or more ACES and increased risk of poor mental and physical health and disability. ${ }^{7}$ The link between ACE and long-term physical and mental conditions is hypothesised as involving the effect of chronic fear and stress on the development of the immune system, which in turn reduces the capacity for allostasis in neurobiological systems and leads to hypothalamic-pituitary-adrenal axis dysfunction. ${ }^{8}$ Given that attachment systems are activated when an individual is stressed, it is not surprising that there is a demonstrable link between a high ACE score and attachment insecurity in adults. ${ }^{9}$

There is a strong relationship between childhood adversity, insecure attachment and later development of long-term conditions in mental health, such as personality dysfunction ${ }^{10}$ and psychotic disorders. ${ }^{11,12}$ However, these same relationships may be seen in those with long-term physical conditions, such as diabetes or 
heart disease. ${ }^{13,14}$ These studies suggest that long-term conditions (whether physical, mental or both) may be the outcome of a process whereby exposure to childhood adversity both stimulates the epigenetic expression of genetic vulnerabilities that affect the risk of developing mental disorders, and leads to the development of an insecure attachment system both in neuroanatomy and selfreported attachment.

Another mediating factor may be the development of language skills. Securely attached individuals are enabled to put emotional and physical experience into words that carers can understand, by developing mentalising skills and an emotional lexicon. ${ }^{15}$ However, insecurely attached individuals may struggle to develop this lexical capacity, and so their distress remains embodied at the unconscious parasympathetic level. ${ }^{16}$ Struggling to articulate emotional aspects of their physical experience, they instead become preoccupied with bodily symptoms and signs. ${ }^{17}$

\section{Attachment theory, mental health services and the therapeutic alliance in psychiatry}

Attachment security not only influences the risk of developing disorders, but also influences healthcare relationships between patients and professionals, especially in the domains of engagement, treatment adherence and treatment fidelity. For example, people with insulin-dependent diabetes and an insecure avoidant attachment style have higher levels of glycosylated haemoglobin that those with secure attachment or preoccupied attachment. ${ }^{18}$ They are also more likely to experience their physician as distant and authoritarian, which may reflect some repetition of an insecure attachment relationship in caregiving contexts.

Current pressures on mental health services can exacerbate patients' insecure attachments because of the emphasis on shortterm episodes of care and the lack of time for relationships to develop. Shortages of staff in all grades and disciplines make it harder to establish the kind of therapeutic alliance that can act as a secure base from which to recover good mental health. Clinicians need to challenge short-term, one-size-fits-all service provision and instead argue for 'psychologically secure' services that people with insecure attachment systems can attach to for reasonable periods of time, and that could help patients 'grow' improved stress management and develop resilience. There is evidence from trials of therapeutic interventions based on attachment theory that 12-18 months of treatment enables positive therapeutic change, ${ }^{19}$ so it would seem reasonable to allow patients to attach to services for around this length of time before discharge, especially those who have histories of disrupted attachments and prior failed therapeutic engagement.

Such services need staff who also feel 'secure' in themselves, and who can process the distress involved in caregiving. Psychiatrists can take a lead in promoting staff resilience, especially acting as 'attachment figures' for trainees who may find core training stressful. Skilling up all disciplines in an understanding of attachment theory and its effect on psychopathology can help staff feel more confident and capable in managing patients with complex needs, especially those with personality disorder and psychosis. A good example of this approach has been developed in the prison service, where a strategy based on attachment theory helps educate and skill up staff in understanding the behaviours of offenders with personality disorders. ${ }^{20}$

As medical psychotherapy services disappear and psychology services are limited, it is vital that all psychiatrists become skilled in making and maintaining therapeutic alliances with patients who have complex needs or find themselves in psychologically demanding situations. An understanding of attachment theory is helpful here because the therapeutic alliance is influenced by attachment security in both patients ${ }^{21,22}$ and staff. ${ }^{23}$ Studies of attachment security in both patients and staff in psychiatric services has provided greater understanding of how staff may misread signals from patients when stressed, leading to ruptures in therapeutic relationships, and staff training can help reduce the risk of this occurring. ${ }^{23}$ Understanding attachment dynamics may be especially important in residential mental health services where patients have complex needs and therapeutic relationships may extend over months or even years. In these settings, parallel processes in terms of anxious attachment can be observed between staff and patients. ${ }^{24}$

Therapies based on attachment theory may be especially helpful for people with complex needs, especially those diagnosed with personality dysfunction, psychotic disorders or both. In these groups, self-reported distress and incoherence of mind reflect impairments in reflective function and meta-cognition that may respond to psychological approaches that specifically address mentalising and metacognitive skills. ${ }^{25}$

\section{Conclusions}

This brief review cannot claim to be comprehensive or provide a nuanced critique of attachment theory; the studies cited here are generally of good quality, but no doubt there are many papers and studies that are methodologically less sound. Nevertheless, I suggest that there is good quality evidence that attachment theory is a paradigm that can help general psychiatrists understand both the genesis of their patients' disorders and the workings of their therapeutic alliances with patients. I also suggest that a working knowledge of attachment theory can help improve services by providing an evidence base for provision of long-term relationships, consistency of staffing and support for carers. Clinicians involved in the development and management of mental health services need to share their knowledge of attachment theory with commissioners, and provide their insight on how this may improve outcomes in the context of long-term care provision for people with mental disorders.

Gwen Adshead, MBBS, MA, FRCPsych, Consultant Forensic Psychiatrist and Psychotherapist, Southern Health NHS Foundation Trust, Hampshire Pathfinder Service, UK

Correspondence: Dr Gwen Adshead, Southern Health NHS Foundation Trust, Hampshire Pathfinder Service, Ravenswood House, Mayles lane, Fareham, Hampshire P017 5NA, UK. Email: g.adshead@nhs.net

First received 8 Feb 2018, final revision 28 Mar 2018, accepted 11 May 2018

\section{References}

1 Bakermans-Kranenburg MJ, van IJzendoorn MH. The first 10,000 Adult Attachment Interviews: distributions of adult attachment representations in clinical and non-clinical groups. Attach Hum Dev 2009; 11(3): 223-63.

2 Vrtička P, Vuilleumier P. Neuroscience of human social interactions and adult attachment style. Front Hum Neurosci 2012; 6: 212.

3 Coan JA. Adult attachment and the brain. J Soc Pers Relat 2010; 27(2): 210-7.

4 Gander M, Buchheim A. Attachment classification, psychophysiology and frontal EEG asymmetry across the lifespan: a review. Front Hum Neurosci 2015; 9: 15.

5 Strathearn L, Fonagy P, Amico J, Montague PR. Adult attachment predicts maternal brain and oxytocin response to infant cues. Neuropsychopharmacology 2009; 34 (13): 2655-6.

6 Lenzi D, Trentini C, Tambelli R, Pantano P. Neural basis of attachment-caregiving systems interaction: insights from neuroimaging studies. Front Psychol 2015; 6: 1241. 
7 Felitti VJ, Anda RF, Nordenberg D, Williamson DF, Spitz AM, Edwards V., et al. Relationship of childhood abuse and household dysfunction to many of the leading causes of death in adults: the Adverse Childhood Experiences (ACE) Study. Am J Prev Med 1998; 14(4): 245-58.

8 Danese A, McEwen BS. Adverse childhood experiences, allostasis, allostatic load, and age-related disease. Physiol Behav 2012; 106(1): 29-39.

9 Murphy A, Steele M, Dube SR, Bate J, Bonuck K, Meissner P, etal. Adverse childhood experiences (ACES) questionnaire and adult attachment interview (AAl): implications for parent child relationships. Child Abuse Neglect 2014; 38(2): 224-33.

10 Lorenzini N, Fonagy P. Attachment and personality disorders: a short review. FOCUS 2013; 11(2): 155-66.

11 Barker V, Gumley A, Schwannauer M, Lawrie SH. An integrated biopsychosocia model of childhood maltreatment and psychosis. Br J Psychiatry 2015; 206(3): 177-80.

12 Korver-Nieberg N, Berry K, Meijer CJ, de Haan L, Ponivsky M. Association between attachment and psychopathology dimensions in a large sample of patients with psychosis. Psychiatry Res 2015; 228(1): 83-8.

13 McWilliams LA, Bailey SJ. Associations between adult attachment ratings and health conditions: evidence from the National Comorbidity Survey Replication. Health Psychol 2010; 29(4): 446-53.

14 Maunder RG, Hunter JJ. Attachment relationships as determinants of physica health. Psychodyn Psychiatry 2008; 36(1): 11

15 Lemche E, Klann-Delius G, Koch R, Joraschky P. Mentalizing language development in a longitudinal attachment sample: implications for alexithymia. Psychother Psychosom 2004; 73(6): 366-74.

16 Schore AN. Effects of a secure attachment relationship on right brain development, affect regulation, and infant mental health. Infant Ment Health J 2001; 22: 7-66.
17 Luyten P, De Meulemeester C. Understanding and treatment of patients with persistent somatic complaints through the lens of contemporary attachment theory. Attachment 2017; 11(3): 205-22.

18 Ciechanowski P, Russo J, Katon W, Von Korff M, Ludman E, Lin E, et al. Influence of patient attachment style on self-care and outcomes in diabetes. Psychosom Med 2004; 66(5): 720-8.

19. National Institute for Health and Care Excellence. Clinical Guideline 78: Borderline Personality Disorder: Recognition and Management. NICE, 2009.

20 Joseph N, Benefield N. A joint offender personality disorder pathway strategy: an outline summary. Crim Behav Ment Health 2012; 22: 210-7.

21 Diener MJ, Monroe JM. The relationship between adult attachment style and therapeutic alliance in individual psychotherapy: a meta-analytic review. Psychotherapy 2011; 48: 237.

22 Berry K, Wearden A, Barrowclough C. Adult attachment styles and psychosis: an investigation of associations between general attachment styles and attachment relationships with specific others. Soc Psychiatry Psychiatr Epidemiol 2007: 42(12): 972-6.

23 Berry K, Shah R, Cook A, Geater E, Barrowclough C, Wearden A. Staff attachment styles: a pilot study investigating the influence of adult attachment styles on staff psychological mindedness and therapeutic relationships. J Clin Psychol 2008; 64(3): 355-63.

24 Schuengel $\mathrm{C}$, van lizendoorn $\mathrm{MH}$. Attachment in mental health institutions: a critical review of assumptions, clinical implications, and research strategies. Attach Hum Dev 2001; 3(3): 304-23.

25 Dimaggio G, Lysaker PH. Metacognition and mentalizing in the psychotherapy of patients with psychosis and personality disorders. J Clin Psychol 2015; 71(2): $117-24$ 